\title{
ARTHROSCOPY FOR PROBLEMS AFTER ANKLE FRACTURE
}

\author{
C. NIEK van DIJK, RONALD A. W. VERHAGEN, JOHANNES L. TOL
}

From the University of Amsterdam, The Netherlands

From 1990 to 1994 we undertook arthroscopy of the ankle on 34 consecutive patients with residual complaints following fracture. Two groups were compared prospectively. Group I comprised 18 patients with complaints which could be attributed clinically to anterior bony or soft-tissue impingement. In group II the complaints of the $\mathbf{1 6}$ patients were more diffuse and despite extensive investigation the definitive diagnosis was not clear before arthroscopy. At the time of the fracture, some osteophytes were already present in $\mathbf{4 1 \%}$ of the patients. These were related to previous supination trauma and participation in soccer.

Arthroscopic treatment consisted of removal of the anteriorly located osteophytes and/or scar tissue. After two years, group I showed a significantly better score for patient satisfaction $(p=\mathbf{0 . 0 2})$. There were $\operatorname{good}$ or excellent results in group $I$ in $76 \%$ and group $I I$ in $43 \%$.

Patients with residual complaints after an ankle fracture and clinical signs of anterior impingement may benefit from arthroscopic surgery. The place for diagnostic ankle arthroscopy is limited.

J Bone Joint Surg [Br] 1997;79-B:280-4.

Received 12 August 1996; Accepted 5 September 1996

Over the last 15 years, clinical experience with ankle arthroscopy has significantly increased ${ }^{1-4}$ but its role in the management of patients with residual complaints following fractures of the ankle has not been determined.

Malunion and the onset of degenerative changes with osteophytes and synovitis are the most important causes of residual complaints after fracture. Malunion of the lateral malleolus changes the biomechanics of the joint. Shortening and lateral rotation of the distal fibula cause widening

C. Niek van Dijk, MD, PhD

R. A. W. Verhagen, MD

J. L. Tol, MSc

Academic Medical Center, University of Amsterdam, Department of

Orthopaedic Surgery, PO Box 22700, 1100 DE Amsterdam, The

Netherlands.

Correspondence should be sent to Dr C. N. van Dijk.

(C)1997 British Editorial Society of Bone and Joint Surgery 0301-620X/97/27153\$2.00 of the ankle mortise and lateral tilt of the talus. Reconstruction is always worthwhile unless function of the ankle is severely impaired. ${ }^{5}$ Promising preliminary results have been obtained with distraction therapy for arthrofibrosis. ${ }^{6}$ Fusion of the ankle may be indicated for symptomatic generalised osteoarthritis.

Complaints after a fracture may be generalised or localised. The anterior impingement syndrome is the most common local problem and arthroscopic resection of osteophytes may be successful. 7,8

The place of arthroscopy in the management of more generalised pain and stiffness is uncertain. Some relief of complaints has been demonstrated after arthroscopic lavage in osteoarthritic knees, ${ }^{9-12}$ but this has not been shown in the ankle. We have compared prospectively the value of arthroscopy in two groups of patients with complaints after ankle fracture. Those in whom corrective osteotomy or arthrodesis was contemplated were excluded.

\section{PATIENTS AND METHODS}

Between 1990 and 1994, 34 consecutive patients with residual complaints after an ankle fracture were assessed. A careful history was taken of their function before and after injury. The findings were recorded on a standard form. Plain radiographs were taken and if the diagnosis remained uncertain a technetium bone scan was performed. This was followed by tomography or a CT scan if these were indicated. Infiltration of the joint with local anaesthetic was undertaken when the investigations were negative. After arthroscopy the patients were reviewed at four months and two years (Figs 1 and 2). A scoring system was used to assess results into four categories. ${ }^{8}$

Arthroscopy was carried out as an outpatient procedure under general or epidural anaesthesia. All the procedures were performed by one surgeon (CNvD). After operation, a compression bandage was applied and partial weight-bearing advised for three to five days. Preoperative radiographs did not show any major deformities or axis deviations, except for one patient with shortening of the fibula of $3 \mathrm{~mm}$ (Fig. 1a). In this patient there was no indication for corrective osteotomy because of the 15-year time interval between the fracture and the start of the complaints.

We identified prospectively two groups of patients. The impingement group (group I) was 10 men and 8 women aged 20 to 42 years (mean 31.9 ) who had complaints which 


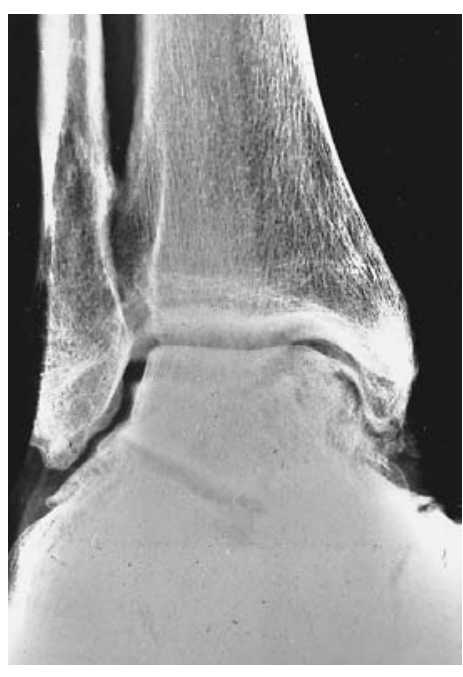

Fig. 1a

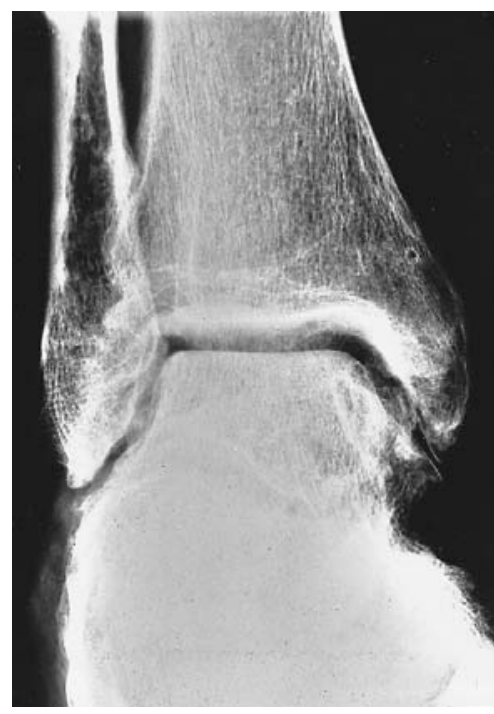

Fig. 2a

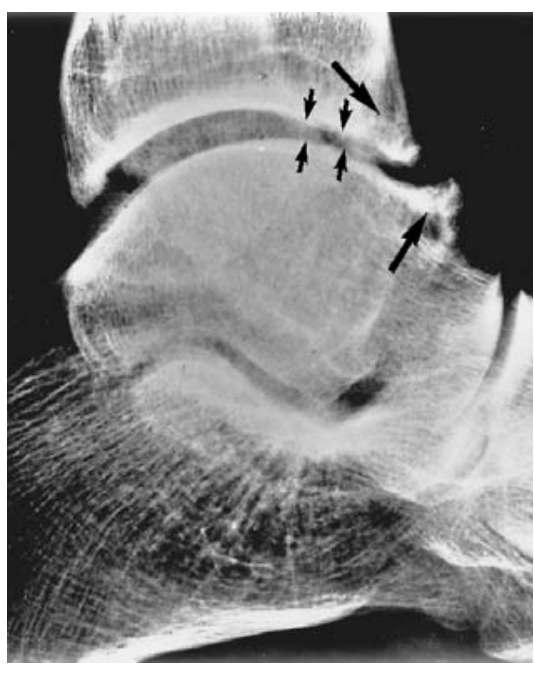

Fig. 1b

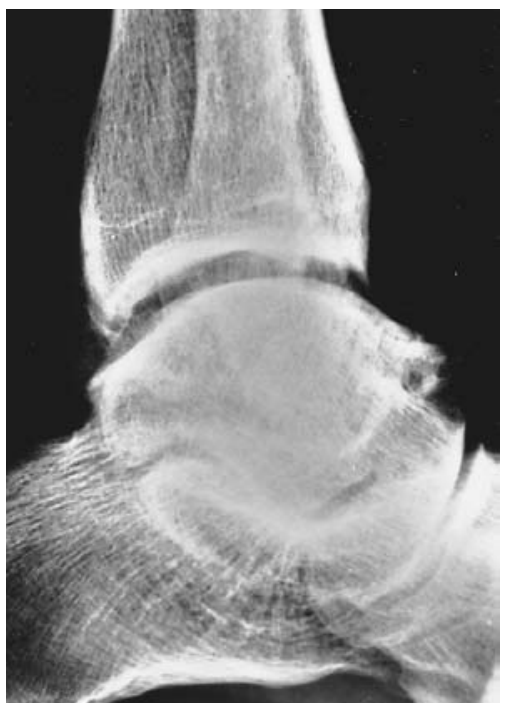

Fig. 2b
Anteroposterior (a) and lateral (b) views of the ankle of a man aged 41 years. Shortening of the fibula is seen on the AP view and narrowing of the joint space and osteophyte formation (grade II osteoarthritis) on the lateral view. He had sustained a fracture of the ankle at the age of 26 and had osteosynthesis of the medial and lateral malleoli.
Anteroposterior (a) and lateral views (b) of the ankle in Figure 1 two years after excision of osteophytes at arthroscopy. The patient was satisfied with the result but had stopped sporting activities because of the rupture of an anterior cruciate ligament. could be attributed clinically to anterior bony or soft-tissue impingement. Their pain was worse on activity and tenderness was localised to the anterior aspect of the ankle and aggravated by passive dorsiflexion. There was restriction of movement, particularly dorsiflexion.

In the diagnostic group (group II) the complaints were more diffuse and there were no specific clinical signs. The definitive diagnosis was not clear before arthroscopy despite full preoperative evaluation. There were $11 \mathrm{men}$ and 5 women aged between 19 and 42 years (mean 29.6).

Impingement lesions were identified according to the criteria of Scranton and McDermott. ${ }^{13}$ We classified osteoarthritis according to the scheme outlined in Table I. Radiographs taken at the time of the original fracture were available in 27 patients together with all those obtained before arthroscopy. Evaluation was undertaken by two independent observers without knowledge of the outcome of the arthroscopy. We used the Mann-Whitney test to compare groups, and Fisher's exact test because of the small numbers.

\section{RESULTS}

One patient in the impingement group and two in the diagnostic group were lost to follow-up. There were no complications following arthroscopy except for one patient who had persisting numbness on the dorsal aspect of the foot.

Table I. A classification of osteoarthritic changes in the ankle Grade $0 \quad$ Normal joint or subchondral sclerosis

I Osteophytes without joint space narrowing

II Joint space narrowing with or without osteophytes

III (Sub)total disappearance or deformation of the joint space 
There were no statistical differences between the groups in length of history (Table II), and age or fracture type (Table III). The Weber A and B, medial malleolar and talar fractures were primarily treated conservatively and the remainder by surgical fixation. The mean time between the fracture and arthroscopy was 6.4 years (SD 5.3 years).

Eleven patients had a history of supination trauma between 6 and 16 years (mean 10 years) prior to the fracture. Twenty-nine participated in sports, of whom 17 played soccer. All patients who had grade I osteoarthritic changes at the time of the fracture had a history of severe supination trauma and/or participation in soccer but in grade 0 lesions only $50 \%$ fell into these categories. This difference is statistically highly significant $(\mathrm{p}=0.004)$.

Osteophytes were removed from 17 patients in group I. In 13 ankles, the lesions were located well within the attachment of the joint capsule and usually at several sites. They were on the anterior part of the medial malleolus in 12 , the anteromedial part of the distal tibia in 10 , the anterolateral part of the distal tibia in five, the medial aspect of the neck of the talus in five and in the lateral aspect in one. Osteoarthritis in these ankles was classified as grade 0 in 1, grade I in 6 and grade II in 10 (Fig. 3).

Removal of scar tissue and partial synovectomy were carried out in 14 patients. Ten of these soft-tissue impingements were located anteromedially and four anterolaterally. Using the classification of Scranton and McDermott ${ }^{13}$ four were grade I, one grade II, five grade III and seven grade IV lesions.

Pain and swelling had diminished in all patients in group I at both reviews. The distribution of the level of pain is shown in Figure 3. Before arthroscopy two

Table II. Length of history in 34 patients having arthroscopy of the ankle

\begin{tabular}{lllll}
\hline & $\begin{array}{l}\text { Impingement } \\
\text { group } \\
\text { (n= 18) }\end{array}$ & \% & $\begin{array}{l}\text { Diagnostic } \\
\text { group } \\
(\mathbf{n = 1 6 )}\end{array}$ & $\%$ \\
\hline 0.5 to $1 \mathrm{yr}$ & 1 & $(6)$ & 0 & $(0)$ \\
1 to $2 \mathrm{yr}$ & 2 & $(11)$ & 1 & $(6)$ \\
2 to $3 \mathrm{yr}$ & 4 & $(22)$ & 6 & $(38)$ \\
$>3 \mathrm{yr}$ & 11 & $(61)$ & 9 & $(56)$ \\
\hline
\end{tabular}

Table III. Type of fracture in 34 patients having arthroscopy of the ankle

\begin{tabular}{lll}
\hline & $\begin{array}{l}\text { Impingement } \\
\text { group } \\
(\mathbf{n}=\mathbf{1 8})\end{array}$ & $\begin{array}{l}\text { Diagnostic } \\
\text { group } \\
(\mathbf{n}=\mathbf{1 6})\end{array}$ \\
\hline Weber A & 0 & 1 \\
Weber B & 3 & 2 \\
Weber C & 5 & 5 \\
Medial malleolus & 2 & 2 \\
Bimalleolar & 2 & 0 \\
Trimalleolar & 1 & 2 \\
Trimalleolar + talus & 0 & 1 \\
Talus & 1 & 1 \\
Pilon & 2 & 0 \\
Unknown & 2 & 2 \\
\hline
\end{tabular}

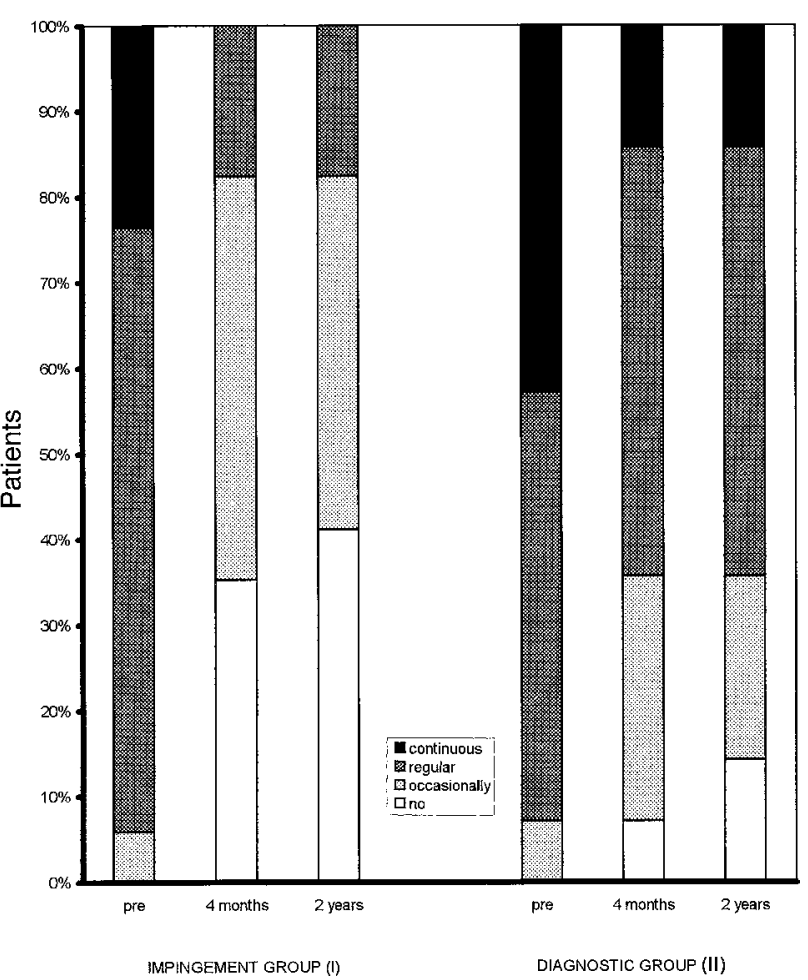

Fig. 3

Pre- and postoperative pain scores.

patients were not able to work but had resumed work when seen after four months; 11 had been unable to play sport but by two years, six had returned to full participation. In four patients dorsiflexion increased by more than $5^{\circ}$ but was unaffected in 13 . The overall result was good or excellent after four months in $82 \%$ and in $76 \%$ at two years. The relationship of patient satisfaction to the degree of osteoarthritis classification after two years is given in Table IV.

In the diagnostic group (group II) the technetium bone scan was negative in five patients and positive in nine, in all of whom MRI or a CT scan showed signs of degenerative changes and synovitis. Apart from joint lavage seven patients had removal of scar tissue and partial synovectomy, four had debridement of the joint cartilage and five removal of osteophytes, all of which were located within the attachment of the joint capsule. Of the soft-tissue lesions seven were classified as grade I, one grade II, two

Table IV. Patient satisfaction (fair/poor) at two years in relation to the classification of osteoarthritis in 31 patients having arthroscopy of the ankle

\begin{tabular}{llllll}
\hline & $\begin{array}{l}\text { Impingement } \\
\text { group } \\
(\mathbf{n}=\mathbf{1 7})\end{array}$ & $(\boldsymbol{\%})$ & $\begin{array}{l}\text { Diagnostic } \\
\text { group } \\
\mathbf{n}=\mathbf{1 4}\end{array}$ & $\mathbf{( \% )}$ \\
\hline Grade & 0 & 0 out of 1 & $(0)$ & 5 out of 5 & $(100)$ \\
I & 1 out of 6 & $(17)$ & 0 out of 3 & $(0)$ \\
II & 3 out of 10 & $(30)$ & 2 out of 3 & $(67)$ \\
III & & & 1 out of 3 & $(33)$ \\
\hline
\end{tabular}


grade III and four grade IV; five of the joints showed grade 0 osteoarthritis, three grade I, three grade II and three grade III. Before arthroscopy two patients were not able to work and they had not been able to resume when reviewed two years later. Nine had been forced to give up sport but three had resumed by two years. By four months the result was graded as good or excellent in $36 \%$ and at two years in $43 \%$.

At the time of fracture 16 of the patients showed grade 0 osteoarthritic changes on the radiographs and 11 had grade I changes. By the time of arthroscopy nine of the grade 0 lesions had progressed to grade I (4) or grade II (5), and the grade I lesions to grade II (5) or grade III (3).

\section{DISCUSSION}

Continuing disability after fracture of the ankle is commonly due to the anterior impingement syndrome. This is characterised by limited, painful dorsiflexion and is caused by either a soft-tissue or bony prominence at the anterior aspect of the joint. ${ }^{8,14,15}$ In general, osteophytes are a secondary manifestation of osteoarthritis, ${ }^{15-17}$ but in the ankle repetitive minor trauma can induce the formation of the spur commonly seen in soccer players and ballet dancers. ${ }^{5,18-20}$ It has been suggested that this is caused by excessive strain on the anterior joint capsule or by repetitive trauma. ${ }^{15,19,21}$

In our study, 18 of the 22 ankles showing tibial and talar osteophytes had them located within the joint capsule and not at the site of attachment of the capsule; hence they could not be due to capsular strain. The lower surface of the anterior tibia and anterior part of the medial malleolus are covered by cartilage. The anterior capsule is attached to the tibia $5 \mathrm{~mm}$ above the joint line. It is this 'non-weightbearing' cartilage rim which undergoes transformation into a spur. Damage to this cartilage rim occurs in the majority of severe supination injuries; ${ }^{22,23}$ depending on the degree of damage, a repair reaction will follow, with cartilage proliferation, formation of scar tissue and calcification. ${ }^{24}$ Further damage due to recurrent instability or forced ankle movements will enhance this process. Recurrent direct microtrauma to this anteriorly located cartilage could be another important factor since some parts lie in a directly subcutaneous position.

Analysis of kicking in soccer demonstrates that ball contact is predominantly with the dorsomedial aspect of the foot and ankle ${ }^{25}$ The kicking velocity is at an average speed of $96 \mathrm{~km} / \mathrm{h} .{ }^{26}$ During a match there are over 60 ball contacts per player and even more occur during training. ${ }^{27}$ Such contacts must produce repetitive microtrauma to the involved structures. Where damage to articular cartilage is already present due to supination or direct trauma, the repetitive kicking of the ball can explain the development of spurs in the so-called 'footballers ankle'. ${ }^{20}$ The weight-bearing articular cartilage is unaffected and these spurs must be differentiated from those of secondary osteoarthritis.

In $41 \%$ of our patients osteophytes were already present at the time of fracture but without joint space narrowing (grade I), and were asymptomatic at the time of the fracture. All these patients had a history of supination trauma and/or participation in soccer. The majority of these patients demonstrated an increase in radiographic evidence of osteoarthritic change between the time of the fracture and arthroscopy.

Our study has shown that a high percentage of good or excellent results may be obtained in grade 0 and I osteoarthritis by arthroscopic removal of anterior impingement lesions. ${ }^{7,8,13,19,28}$ Because of the associated degenerative change the results are not quite as good in ankles with grade II osteoarthritis. Lavage alone did not produce the satisfactory results reported in the knee. ${ }^{8,10-12}$ A firm diagnosis must be established before arthroscopy is undertaken since more generalised post-traumatic disorders such as cartilage deformation, incongruity or arthrofibrosis are not improved by this procedure. Arthroscopy for diagnosis alone is of limited value.

No benefits in any form have been received or will be received from a commercial party related directly or indirectly to the subject of this article.

\section{REFERENCES}

1. Drez D, Guhl JF, Gollehon DL. Ankle arthroscopy: technique and indications. Foot Ankle 1981;2:138.

2. Ferkel RD, Fischer SP. Progress in ankle arthroscopy. Clin Orthop 1989;240:210-20.

3. Guhl JF. New techniques for arthroscopic surgery of the ankle: preliminary report. Orthopedics 1986;9:261-9.

4. Parisien JS, Vangsness T. Operative arthroscopy of the ankle: three years' experience. Clin Orthop 1985;199:46-53.

5. Marti RK, Raaymakers ELFB, Nolte PA. Malunited ankle fractures: the late results of reconstruction. J Bone Joint Surg [Br] 1990; 72-B:709-13.

6. Valburg van AA, Roermund van PM, Lammens J, et al. Can Ilizarov joint distraction delay the need for an arthrodesis of the ankle? a preliminary report. J Bone Joint Surg [Br] 1995;77-B:720-5.

7. Ferkel RD, Scranton PE. Arthroscopy of the ankle and foot. $J$ Bone Joint Surg [Am] 1993;75-A:1233-42.

8. Ogilvie-Harris DJ, Mahomed N, Demaziére A. Anterior impingement of the ankle treated by arthroscopic removal of bony spurs. J Bone Joint Surg [Br] 1993;75-B:437-40.

9. Jackson RW. The role of arthroscopy in the management of the arthritic knee. Clin Orthop 1974;101:28-35.

10. Edelson R, Burks RT, Bloebaum RD. Short-term effects of knee washout for osteoarthritis. Am J Sports Med 1995;23:345-9.

11. Ogilvie-Harris DJ, Fitsialos DP. Arthroscopic management of the degenerative knee. Arthroscopy 1991;7:151-7.

12. Livesley PJ, Doherty M, Needoff M, Moulton A. Arthroscopic lavage of osteoarthritic knees. J Bone Joint Surg [Br] 1991;73-B: 922-6.

13. Scranton PE, McDermott JE. Anterior tibiotalar spurs: a comparison of open versus arthroscopic debridement. Foot Ankle 1992;13:125-9.

14. Van Dijk CN, Fiévez AWFM, Heijboer MP, et al. Arthroscopy of the ankle. Acta Orthop Scand 1993;64:9(S253).

15. O'Donoghue DH. Impingement exostoses of the talus and tibia. J Bone Joint Surg [Am] 1957;39-A:835.

16. Hermodson I. The development of coxarthrosis: a radiological follow-up of patients operated upon. Radiologe 1983;23:378-84.

17. Walter JH, Spector A. Traumatic osteoarthrosis of the ankle joint secondary to ankle fractures. J Am Podiatr Med Assoc 1991;81: 399-405. 
18. Van Dijk CN, Lim LS, Poortman A, Strübbe EH, Marti RK. Degenerative joint disease in female ballet dancers. Am J Sports Med 1995;23: 295-300.

19. Biedert R. Anterior ankle pain in sports medicine: aetiology and indications for arthroscopy. Arch Orthop Trauma Surg 1991;110: 293-7.

20. McMurray TP. Footballers ankle. J Bone Joint Surg [Br] 1950; 32-B:68-9.

21. Morris LH. Report of cases of athlete's ankle. J Bone Joint Surg [Am] 1943;25:220.

22. Van Dijk CN. On diagnostic strategies in patients with severe ankle sprain. Amsterdam, Thesis, 1994.

23. Van Dijk CN, Bossuyt PMM, Marti RK. Medial ankle pain after lateral ligament rupture. J Bone Joint Surg [Br] 1996;78-B:562-7.
24. Mankin HJ. The response of articular cartilage to mechanical injury. J Bone Joint Surg [Am] 1982;64-A:460-6.

25. Lees A Kewley P. The biomechanics of football. In: Reilly T, Clarys J, Stibbe A, eds. Science and football. London: E and FN Spon, 1993;327-34.

26. Taiana JF, Cometti G. The influence of maximal strength training in lower limbs of soccer players on their physical kick performances. In: Reilly T, Clarys J, Stibbe A, eds. Science and football. London: E and FN Spon, 1993;98-103

27. Lees A, Kewley P. The demands on the soccer boot. In: Reilly T, Clarys J, Stibbe A, eds. Science and football. London: E and FN Spon, 1993;335-40.

28. Liu SH, Raskin A, Osti L, et al. Arthroscopic treatment of anterolateral ankle impingement. Arthroscopy 1994;10:215-8. 